\title{
Local variability in respiratory syncytial virus disease severity
}

Afke H Brandenburg, Pierre-Yves Jeannet, Henriette A v Steensel-Moll, Alewijn Ott, Philip H Rothbarth, Werner Wunderli, Susanne Suter, Herman J Neijens, Albert D M E Osterhaus, Claire-Anne Siegrist

Department of Virology, Erasmus University Rotterdam, Netherlands A H Brandenburg P H Rothbarth A D M E Osterhaus

Department of Paediatrics, Geneva University Hospital, Switzerland

P-Y Jeannet

S Suter

C-A Siegrist

Department of Paediatrics, Sophia Children's Hospital, Rotterdam,

Netherlands H A v Steensel-Moll H J Neijens

Department of Epidemiology and Biostatistics, Erasmus University, Rotterdam, Netherlands A Ott

Laboratory of Virology, Geneva University Hospital, Switzerland W Wunderli

Correspondence to: Dr Claire-Anne Siegrist, Department of Paediatrics, Geneva University Hospital, 1211 Geneva 14, Switzerland.

Accepted 15 July 1997

\begin{abstract}
Respiratory syncytial virus (RSV) lower respiratory tract infections are considered to be a serious disease in centres such as the Sophia Children's Hospital (Rotterdam, the Netherlands), but as more benign infections in others such as the Geneva Children's Hospital (Switzerland). To assess the clinical severity of RSV infections at the two sites, 151 infants primarily admitted with a virologically confirmed RSV infection were studied prospectively (1994-5) and retrospectively (1993-4) (55 infants in Geneva and 96 in Rotterdam). Parameters of RSV morbidity which were more severe in Rotterdam during the two winter seasons were apnoea $(1.8 v 23.9 \%)$, the rate of admission to the intensive care unit (3.6 $v \quad 28.1 \%)$, mechanical ventilation $(0 \quad v \quad 7.3 \%)$, and length of stay in hospital (6.8 $v 9.1$ days). In Geneva higher respiratory rates $(59.2 v$ $51.2)$, more wheezing (65.5 $v 28.8 \%)$, and more retractions $(81.8$ v $63.3 \%)$ were recorded. Fewer infants younger than 4 months (54.9 $v 68.7 \%$ ), but more breast fed infants $(94.1 v 38.5 \%)$, were admitted in Geneva, although the morbidity parameters remained different after correction for these two variables in multivariate analyses. Thus unidentified local factors influence the pattern and severity of RSV infection and may affect the results of multicentre prophylactic and therapeutic studies.

(Arch Dis Child 1997;77:410-414)
\end{abstract}

Keywords: respiratory syncytial virus; acute respiratory infections; bronchiolitis

Respiratory syncytial virus (RSV) is the most common cause of lower respiratory tract infection (for example, bronchiolitis, pneumonia) in young children. RSV infections occur in yearly winter epidemics and most children are infected before the age of 2 years. ${ }^{12}$ The highest morbidity of RSV disease is seen in infants aged less than 6 months ${ }^{3-6}$ and in children with risk factors such as prematurity, ${ }^{7}$ bronchopulmonary dysplasia, ${ }^{8}$ congenital heart disease with pulmonary hypertension, ${ }^{9}$ or immune deficiency. ${ }^{10}$ An estimated $0.5-2 \%$ of all infants with RSV infection are admitted to hospital $^{3-5} 7^{11}$ and $7-21 \%$ of these infants will develop respiratory insufficiency and require respiratory support. ${ }^{12-14}$ The proportion of infants eventually dying from RSV infection has been estimated at $0.5-1.5 \%$ of all infants admitted to hospital, and higher mortality is seen in infants with underlying disease..$^{15} 16$

This classically described RSV morbidity, however, does not reflect the RSV morbidity observed in the Geneva Children's Hospital (Switzerland), where RSV bronchiolitis is considered a common, but relatively benign, disease, in spite of an annual birth cohort including all defined risk groups. Over the past 10 years few infants admitted to hospital in Geneva with an RSV infection developed respiratory insufficiency requiring respiratory support, and no death directly attributable to RSV was reported. In contrast, RSV disease is considered a serious, sometimes life threatening, disease at the Sophia Children's Hospital (Rotterdam, the Netherlands).

In the present study we compared the clinical characteristics and outcome of disease in infants admitted to hospital with RSV infections in these two centres (a) to objectively assess the morbidity of RSV infections at each site and thus the local potential for preventive or therapeutic measures and (b) to evaluate whether known parameters of disease severity explain the local variability of clinical characteristics and outcome of RSV disease in infants.

\section{Patients and methods}

All children less than 12 months of age admitted to the Geneva Children's Hospital or the Sophia Children's Hospital, Rotterdam with a virologically confirmed RSV infection in the winter seasons 1993-4 and 1994-5 were included in the study. The study was approved by institutional ethical committees from the two hospitals. The RSV infection was defined as a positive result in direct immune fluorescence assay performed on cells from nasopharyngeal washings using fluorescein isothiocyanate labelled RSV specific monoclonal antibodies (DAKO, Ely) or detection of the viral antigen by indirect ELISA ${ }^{17}$ and subsequent confirmation by viral culture. Duplicate samples collected in Geneva were frozen and sent to the department of virology of Erasmus University for confirmation analyses. Children referred by other hospitals and nosocomially infected children were excluded from the analyses to minimise the potential influence of different referral systems.

The Geneva Children's Hospital is a university hospital providing primary, secondary, and tertiary care for a population of approximately 
500000 inhabitants with an annual cohort of 5800 births in 1994 . As it is the only children's hospital it admits all infants from this defined area, including all prematurely born infants. The Sophia Children's Hospital, Rotterdam is a university hospital with a combined secondary-tertiary care function. As one of several hospitals in the area it admits only some of the children from the Rotterdam area requiring admission to hospital. Most patients seen in the emergency care outpatient clinic of the Sophia Children's Hospital receive basic paediatric care $(90 \%)$ and only $17 \%$ come from outside the Rotterdam area. ${ }^{18}$

Epidemiological and clinical variables were prospectively obtained on admission and discharge or at a control visit for the season 1994-5, and retrospectively from the patient charts for the season 1993-4. Demographic and clinical data were recorded on a standardised form with common definitions for all items. The demographic variables included gender, age, duration of pregnancy, existence of underlying disease (defined as congenital heart disease, bronchopulmonary dysplasia, or $\mathrm{T}$ cell immune deficiency), breast feeding, a positive family history of asthma or eczema, number of children in the household, day care attendance, and smoking in the household. The clinical data included the number of days with breathing problems before admission, feeding difficulties (defined as an increase of time required for feeding or a decrease in feeding volume), a positive history of apnoea (defined as either a history of respiratory arrest with cyanosis or an observation of respiratory arrest for a period of more than 20 seconds and/or bradycardia with accompanying cyanosis in the paediatric emergency room or during hospital admission), respiratory rate, the presence of wheezing (scored positive if wheezing could be heard without using a stethoscope) and retractions, fever (defined as a rectal temperature higher than $38.5^{\circ} \mathrm{C}$ ), oxygen saturation $\left(\mathrm{SaO}_{2}\right)$ in room air, carbon dioxide tension $\left(\mathrm{PCO}_{2}\right), \mathrm{pH}$, and abnormalities on a radiograph (hyperinflation, consolidation, or atelectasis) as described by the radiologist. $\mathrm{SaO}_{2}$ was meas-

Table 1 Demographic characteristics of patients; values are number (\%) unless otherwise stated

\begin{tabular}{|c|c|c|c|}
\hline & Geneva $(n=55)$ & Rotterdam $(n=96)$ & $p$ Value \\
\hline Sex (boys:girls) & $34: 21$ & $55: 41$ & 0.71 \\
\hline Median (range) at admission (days) & $108(11-341)$ & $79(9-256)$ & 0.17 \\
\hline Mean (SD) gestational age (weeks) & $38.2(3.3)$ & $38.0(3.0)$ & 0.79 \\
\hline \multicolumn{4}{|l|}{ Risk factors } \\
\hline Gestation $<37$ weeks & $10(18.2)$ & $23(24.0)$ & 0.53 \\
\hline Age $<6$ weeks & $9(16.4)$ & $23(24.0)$ & 0.37 \\
\hline Cardiac malformation & $2(3.6)$ & $3(3.1)$ & \\
\hline Bronchopulmonary dysplasia & $2(3.6)$ & $4(4.2)$ & \\
\hline $\mathrm{T}$ cell immune deficiency & 0 & 0 & \\
\hline No risk factor & $34(61.8)$ & $53(55.2)$ & 0.53 \\
\hline \multicolumn{4}{|l|}{ Breast feeding } \\
\hline$>1$ month & $35(70.0)$ & $23(29.1)$ & 0.0001 \\
\hline At admission & $25(50.0)$ & $24(31.2)$ & 0.051 \\
\hline Asthma in family* & $8(25.8)$ & $14(26.4)$ & 1.00 \\
\hline Eczema in family ${ }^{\star}$ & $2(6.5)$ & $10(18.5)$ & 0.20 \\
\hline Median (range) No of children in the household ${ }^{\star}$ & $2(1-4)$ & $2(1-8)$ & 1.00 \\
\hline Daycare attendance ${ }^{\star}$ & $3(9.7)$ & $3(5.7)$ & 0.67 \\
\hline Smoking in the household ${ }^{\star}$ & $12(40.0)$ & $23(46.9)$ & 0.64 \\
\hline
\end{tabular}

^ Data from the prospectively collected cohort (season 1994-5) only.

Differences between Geneva and Rotterdam cohorts were tested by the $\chi^{2}$ or Fisher's exact test for dichotomous variables and by Mann-Whitney $U$ test for continuous variables. ured transcutaneously with the use of a pulse oximeter (Hewlett Packard Neonatal (Rotterdam), Nellcor N-180 (Geneva)). Intubation was indicated in both centres in the case of (a) respiratory insufficiency with hypercapnia $\left(\mathrm{PCO}_{2}>8 \mathrm{kPa}\right.$ and $\left.\mathrm{pH}<7.2\right)$, (b) hypoxia $\left(\mathrm{SaO}_{2}\right.$ $<85 \%$ with a fractional inspired oxygen $>60 \%$ ), (c) prolonged episodes of apnoea leading to severe bradycardia requiring stimulation or hand bag ventilation, or (d) sudden clinical deterioration. Discharge from either hospital required an adequate fluid intake for age, correction of tachypnea, and no oxygen requirement.

Data collected on the course of the disease and treatment included the occurrence of additional apnoea during the hospital stay, the maximum respiratory rate, the length of stay in hospital, admission to and length of stay in the intensive care unit, use of mechanical ventilation, administration of oxygen, bronchodilators, ribavirine and/or antibiotics, and number of deaths.

The clinical data from the Geneva and Rotterdam patients were compared in a $\chi^{2}$ test, Fisher's exact test, or Mann-Whitney U test when applicable. Differences in the clinical manifestations between Geneva and Rotterdam were tested again with multiple regression analysis, adjusting for possible confounders. Linear regression was used for continuous variables and logistic regression for dichotomous variables. The clinical parameters were entered in the regression model as dependent variables, and the confounders and location were entered as independent variables. Statistical significance was accepted at $\mathrm{p}<0.05$. To check for seasonal differences in clinical severity the analyses were also performed separately for the two winter seasons.

\section{Results}

RATES OF ADMISSION TO HOSPITAL IN GENEVA We calculated the rates of admission to hospital for RSV infection in the Geneva Children's Hospital for both term $(n=5800)$ and preterm (gestation <37 weeks, $\mathrm{n}=312$ ) infants younger than 12 months of age. The rate of admission to hospital was 5.3/1000 for term and 22/1000 for preterm infants for the 1994-5 winter season. The rate of admission to hospital in Rotterdam could not be reliably calculated as the size of the attachment population for the Sophia Children's Hospital cannot be precisely defined.

\section{DEMOGRAPHICS}

A total of 208 children younger than 12 months of age (61 in Geneva, 147 in Rotterdam) were admitted to hospital with a diagnosis of RSV infection. A predominance of RSV subgroup A was found in nasopharyngeal specimens in the two centres (Rotterdam, 1993-4 60\% subgroup A, 1994-5 100\% subgroup A; Geneva, 1993-4, data not available, 1994-5 75\% subgroup A). Six infants in Geneva (one secondary referral and five nosocomial infections) and 51 in Rotterdam (27 secondary referrals and 24 nosocomial infections) were excluded from the analysis. 


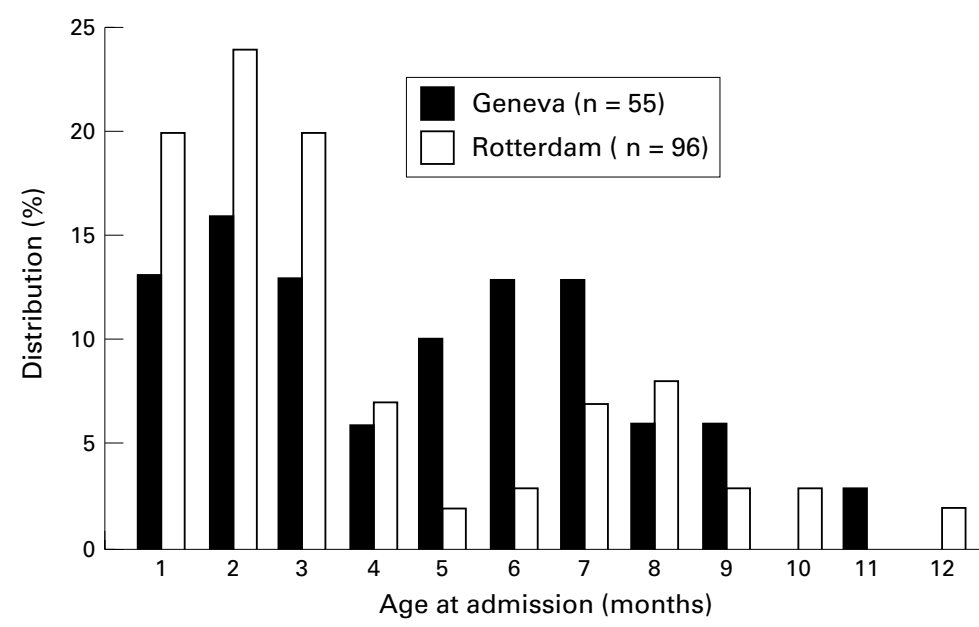

Figure 1 Age distribution of infants less than 12 months admitted to hospital for RSV disease in two European children's hospitals.

Table 2 Clinical parameters at admission; values are number (\%) unless otherwise stated

\begin{tabular}{llll}
\hline & $\begin{array}{l}\text { Geneva } \\
(n=55)\end{array}$ & $\begin{array}{l}\text { Rotterdam } \\
(n=96)\end{array}$ & $p$ Value \\
\hline $\begin{array}{l}\text { Fever } \\
\begin{array}{l}\text { Median (range) days with breathing problems before } \\
\text { admission }\end{array}\end{array}$ & $\begin{array}{l}15(27.2) \\
3(0-13)\end{array}$ & $\begin{array}{l}22(23.4) \\
2(0-9)\end{array}$ & 0.74 \\
$\begin{array}{l}\text { Feeding problems } \\
\text { Retractions }\end{array}$ & $42(76.4)$ & $82(92.1)$ & 0.09 \\
Wheezing & $45(81.8)$ & $57(63.3)$ & 0.17 \\
Mean (SD) respiratory rate/minute & $19(65.5)$ & $17(28.8)$ & 0.001 \\
Apnoea & $59.7(12.2)$ & $51.2(19.1)$ & 0.0002 \\
Mean (SD) $\mathrm{SaO}_{2}$ & $1(1.8)$ & $23(23.9)$ & 0.0008 \\
Mean (SD) $\mathrm{PCO}_{2}$ & $92.5(8.2)$ & $90.8(9.0)$ & 0.0039 \\
Abnormality on radiograph & $5.8(1.3)$ & $6.7(1.9)$ & 0.032 \\
& $(\mathrm{n}=15)$ & $(\mathrm{n}=94)$ & 0.10 \\
\hline
\end{tabular}

* Data from the prospectively collected cohort (season 1994-5) only.

Differences between Geneva and Rotterdam cohorts were tested by the $\chi^{2}$ or Fisher's exact test for dichotomous variables and by Mann-Whitney U test for continuous variables.

Table 3 Course of disease and treatment; values are number (\%) unless otherwise stated

\begin{tabular}{llll}
\hline & Geneva $(n=55)$ & Rotterdam $(n=96)$ & $p$ Value \\
\hline Children requiring & $43(78.8)$ & $59(68.6)$ & 0.30 \\
$\quad$ Oxygen administration & $49(89.1)$ & $79(84.0)$ & 0.54 \\
Bronchodilators & 0 & $16(17.2)$ & \\
Ribavirin & $32(58.2)$ & $34(38.2)$ & 0.03 \\
Antibiotics & $63.3(12.3)$ & $58.7(15.4)$ & 0.026 \\
Mean (SD) maximum respiratory rate & 0 & $2(2.1)$ & \\
Additional children with apnoea & $2(3.6)$ & $27(28.1)$ & 0.0005 \\
Patients in intensive care unit & 0 & $7(7.3)$ & 0.048 \\
Patient requiring mechanical ventilation & 0 & $1(1.0)$ & 0.0011 \\
Deaths & $6.5(1-19)$ & $9(1-29)$ & \\
Median (range) hospital stay (days) & &
\end{tabular}

Differences between Geneva and Rotterdam cohorts were tested by the $\chi^{2}$ or Fisher's exact test for dichotomous variables and by Mann-Whitney $U$ test for continuous variables.

Table 1 summarises the demographic data on the 151 children included in the study. Significant differences between centres were only noted for breast feeding (table 1) and age at admission (fig 1): $55 \%$ of children admitted in Geneva and $69 \%$ of those admitted in Rotterdam were younger than 4 months $\left(\chi^{2}\right.$ test; $\mathrm{p}=$ 0.03).

DISEASE SEVERITY AT ADMISSION

Several disease severity parameters were reported differently by the two centres (table 2). Rotterdam infants were more often admitted with a history of apnoea and had a lower $\mathrm{SaO}_{2}$ and a higher $\mathrm{PCO}_{2}$ at the time of admission than the subset of Geneva infants for whom $\mathrm{PCO}_{2}$ values were available. Geneva infants, in contrast, had a higher mean respiratory rate and more often presented with wheezing and chest retractions. Feeding difficulties and chest retractions were the most common presenting symptoms in the two centres.

COURSE OF DISEASE AND TREATMENT

Treatment in the two centres included supplementary oxygen, empirical bronchodilator administration, and the use of antibiotics but no corticosteroids (table 3). Ribavirin was only used for a subset of infants in Rotterdam. Additional episodes of apnoea (two infants) were only reported in Rotterdam, as well as the death of a 4 week old infant with no known RSV risk factors who had been admitted with cardiorespiratory arrest after recurrent apnoea. The total length of stay in hospital was shorter in Geneva than in Rotterdam, where more children were admitted to the intensive care unit and required mechanical ventilation.

\section{SEPARATE ANALYSIS OF SEASONS}

To evaluate the influence of seasonal variability on the clinical severity of RSV, statistical analyses were performed independently for the prospectively studied 1994-5 winter season and the retrospective 1993-4 season. For the 1994-5 season, no difference in pre-existing risk factors was observed between Geneva $(\mathrm{n}=$ $31)$ and Rotterdam $(n=59)$ infants. Significant differences for Geneva infants were higher rates of breast feeding $>1$ month $(74.2 v 30.6 \%, \mathrm{p}<$ $0.001)$, higher respiratory rates $(60.3 v 51.3, \mathrm{p}$ $=0.019)$, a lower frequency of apnoea (3.2 $v$ $23.7 \%, \mathrm{p}=0.013$ ), lower $\mathrm{PCO}_{2}$ (5.65 v 6.91, p $=0.019)$, a shorter length of hospital stay (6.0 $v 8.4$ days, $\mathrm{p}=0.01$ ), and a lower rate of admission to the intensive care unit $(6.5 v$ $32.2 \%, p<0.001)$. In this small sample of 90 infants differences in the frequency of chest retractions, mean $\mathrm{SaO}_{2}$, and requirement for respiratory support did not reach statistical significance. The same trends were found for the 1993-4 season (24 infants in Geneva and 37 in Rotterdam). Significant differences for the Geneva infants were a higher rate of breast feeding $>1$ month (73.4 $v 21.8 \%, \mathrm{p}=0.002)$, a higher mean respiratory rate $(59.5 v 51.1, \mathrm{p}=$ $0.03)$, a lower frequency of apnoea ( $0 v 24.3 \%$, $\mathrm{p}=0.009)$, a shorter length of hospital stay (7.3 $v 9.9$ days, $\mathrm{p}=0.02$ ), and a lower rate of admission to the intensive care unit ( $0 v$ $21.6 \%, p=0.02)$.

\section{MULTIVARIATE ANALYSIS}

Clinical parameters which differed significantly between Geneva and Rotterdam were again compared by multivariate analysis, adjusting for the identified epidemiological factors that differed between the two centres-namely, age and breast feeding. After correction for these potential confounders a higher percentage of apnoeas, a higher rate of admission to the intensive care unit, and a longer duration of hospital stay were still observed in Rotterdam, whereas a higher respiratory rate and higher percentage of wheezing on admission in Geneva remained significant. 


\section{Discussion}

In this study we confirmed that the course of RSV infections is significantly more benign in Geneva than Rotterdam. Infants admitted to hospital in Geneva less often presented with apnoea or respiratory insufficiency and thus less often required admission to the intensive care unit or respiratory support than infants admitted in Rotterdam. Their more benign status was also reflected by a significantly shorter length of stay in hospital. This demonstration of a local variability of RSV disease severity is not restricted to the two centres studied. It is in accordance with at least two previous published observations. A striking difference in RSV morbidity was first reported in 1961 in two nearby nursery groups..$^{19}$ More recently, a significant association between the hospital centre and parameters of clinical severity was reported in a multicentre study of RSV outcome in Canada. ${ }^{20}$ Furthermore, paediatricians from various European centres have subjectively recognised either of the two distinct clinical patterns of RSV disease presented here as representative of the situation prevailing in their area (personal communications to C A Siegrist at ESPID meeting, June 1996). Importantly, this study also shows (as 35 years ago $^{19}$ ) that a detailed comparison of all the parameters previously reported as affecting disease severity does not identify the factors responsible for the observed differences in RSV disease severity.

The more benign course of RSV infection in Geneva does not appear to depend on a lower incidence of RSV infections in the first year of life. The rate of admission to hospital for an RSV infection during the first winter season at $5.3 / 1000$ lies within the previously reported rates of admission to hospital of $1-20 / 1000$ children. ${ }^{321}$ This rate of admission to hospital in Geneva is little affected by the variable severity of the RSV winter epidemic. Comparison of the two consecutive seasons of children admitted to hospital confirmed that the disease pattern and severity also remain constant. As rates of admission to hospital have been reported to be influenced by socioeconomic status, influencing the age at exposure and access to medical care ${ }^{21-23}$ the potentially higher socioeconomic status of parents in Geneva would be expected to result in a reduction of rates of admission to hospital rather than of RSV disease severity. Thus the more benign course of RSV disease in Geneva than in Rotterdam essentially reflects a reduced severity of disease in the most severely sick infants who require admission to hospital.

Disease severity and the outcome of infants admitted to hospital is related to their preexisting status such as prematurity, age less than 6 weeks, congenital heart disease, bronchopulmonary dysplasia, or immune deficiency. ${ }^{79}$ The lower severity of RSV infections in Geneva than Rotterdam is, however, not explained by a lower number of infants presenting with these underlying risk factors. Two factors found to differ between the two cohorts were a smaller percentage of children aged less than 4 months at admission and a higher percentage of breast feeding in Geneva. Interestingly, the percentage of breast fed infants in the Rotterdam cohort was also significantly lower than the overall rate of breast feeding in the Netherlands $(65 \%$ at 1 month and $55 \%$ at 3 months of age $\left.^{24}\right)$. As minimal or no breast feeding has been reported to increase the risk of admission to hospital for respiratory infections, ${ }^{21}$ mucosal protection could participate in the observed reduction of disease severity. Correcting for breast feeding and age in multivariate analyses did not correct the differences in disease severity, however.

Differences in subtype virulence have also been suggested to explain the yearly variation of disease severity, ${ }^{25} 26$ although no relation between clinical severity and RSV subtypes was found in a study in Rotterdam. ${ }^{27}$ In the present study a predominance of subtype A was observed in Geneva and in Rotterdam. Although virulence could still differ within strains of the same subtype, strain virulence differences are unlikely to result in a higher morbidity in the same centre over two consecutive winter seasons.

Other epidemiological factors that could explain the reported variation in disease severity (see under methods) were carefully compared and found to be similar in the two cohorts. Differences in referral systems were minimised in our study by only including primarily referred infants to either centre, but differences in hospital policies still affect rates of admission to the intensive care unit. In Rotterdam all RSV infected children less than 2 months of age or born prematurely are initially monitored in the intensive care unit, whereas admission to the Geneva intensive care unit depends exclusively on the clinical status. These hospital policies cannot, however, explain the differences in clinical parameters at admission or indication for mechanical ventilation.

Unexpectedly, we recognised two different disease patterns in our two cohorts: respiratory rate and frequency of wheezing and chest retractions were significantly higher in the Geneva infants. In contrast, respiratory insufficiency was more common in Rotterdam, although the duration of reported respiratory symptoms before admission was shorter. We postulate that the efficacy of compensatory hyperventilation in response to lung disease could be a critical factor distinguishing the two cohorts. This dissociation between an increased respiratory effort (previously described as a poor predictor of clinical severity ${ }^{28}$ ) and the clinical outcome suggests that environmental factors such as air quality may exert an influence on RSV morbidity by modulating the infant's capacity to respond to pulmonary disease by compensatory hyperventilation. Parental smoking (similar in the two cohorts) and the use of wood burning stoves ${ }^{23} 2^{30}$ have been shown to increase the risk and severity of RSV infections. It is important to define the role of air humidity or temperature, either indoors or outdoors, or of industrial air pollution, which is responsible for an excess of cardiovascular deaths among adult or elderly patients ${ }^{31}$ and which could also affect the capacity of young 
infants to cope with respiratory infections. ${ }^{32} \mathrm{~A}$ relatively preserved air quality in medium sized cities such as Geneva compared with large industrialised urban agglomerations such as Rotterdam could well contribute to a lower morbidity of infant respiratory diseases. Air quality could thus contribute to the high RSV morbidity reported by large American or European centres, mostly located in dense urban environments.

In conclusion, parameters to be collected in multicentre studies assessing RSV disease severity have not yet all been identified. Whether air quality affects RSV disease in infants and elderly patients should be specifically addressed through prospective studies collecting air samples. Until these additional factors responsible for the geographical variations of RSV morbidity are identified, the many prophylactic or therapeutic strategies planned for the next decade should probably take into careful account the existence of different local disease patterns.

We are indebted to Martin Kneijber for help in collecting patient data and to Albert Z Kapikian (National Institute of Health Bethesda, MD) and Ron Dagan (Soroka University Medical Center, Ben-Gurion University of the Negev, Beer-Sheva, Israel) for helpful challenging discussions about these observations.

1 Glezen WP, Taber LH, Frank AL, Kasel JA. Risk of primary infection and reinfection with respiratory syncytial virus. Am $\mathcal{F}$ Dis Child 1986;140:543-6.

$2 \mathrm{Kim} \mathrm{HW}$, Arrobio JO, Brandt CD, et al. Epidemiology of respiratory syncytial virus infection in Washington, DC. I. Importance of the virus in different respiratory tract disease syndromes and temporal distribution of infection. $A m \mathcal{F}$ Epidemiol 1973;98:216-25.

3 Glezen WP, Paredes A, Allison JE, Taber LH, Frank AL. Risk of respiratory syncytial virus infection for infants from low-income families in relationship to age, sex, ethnic low-incom 15.

4 Green M, Brayer AF, Schenkman KA, Wald ER. Duration of hospitalization in previously well infants with respiratory
syncytial virus infection. Pediatr Infect Dis $\mathcal{f} 1989 ; 8: 601-5$.

5 Hall CB, Hall WJ, Speers DM. Clinical and physiological Hall CB, Hall WJ, Speers DM. Clinical and physiological
manifestations of bronchiolitis and pneumonia: outcome of manifestations of bronchiolitis and pneumonia: outcome of 802 .

6 Parrot RH, Kim HW, Arrobio JO, et al. Epidemiology of respiratory syncytial virus infection in Washington, DC. II Infection and disease with respect to age, immunologic status, race and sex. Am F Epidemiol 1973;98:289-300.

7 Navas L, Wang E, de Carvalho V, Robinson J. Improved outcome of respiratory syncytial virus infection in a high-risk hospitalized population of Canadian children. Pediatric Investigators Collaborative Network on Infections in Canada. F Pediatr 1992;121:348-54.

8 Groothuis JR, Gutierrez KM, Lauer BA. Respiratory syncytial virus infection in children with bronchopulmonary dysplasia. Pediatrics 1988;82:199-203.

9 MacDonald NE, Hall CB, Suffin SC, Alexon C, Harris PJ, Manning JA. Respiratory syncytial viral infection in infants Manning JA. Respiratory syncytial viral infection in infants
with congenital heart disease. N Engl f Med 1982;307:397with 400 .

10 Hall CB, Powell KR, McDonald NE, et al. Respiratory syncytial viral infection in children with compromised immune function. $N$ Engl f Med 1986;315;77-81.
11 Martin AJ, Gardner PS, McQuillin J. Epidemiology of respiratory viral infection among paediatric inpatients over a six year period in north-east England. Lancet 1978;ii: 1035-8.

12 Everard ML, Milner AD. The respiratory syncytial virus and its role in acute bronchiolitis. Eur f Pediatr 1992;151:63851.

13 Frankel LR, Lewiston NJ, Smith DW, Stevenson DK. Clinical observations on mechanical ventilation for respiratory failure in bronchiolitis. Pediatr Pulmonol 1986;79:307-11.

14 Tissing WJ, van Steensel-Moll HA, Offringa M. Risk factors for mechanical ventilation in respiratory syncytial virus infection. Eur F Pediatr 1993;152:125-7.

15 La Via WV, Grant SW, Stutman HR, Marks MI. Clinical profile of pediatric patients hospitalized with respiratory syncytial virus infection. Clin Pediatr (Phila) 1993;32;4504.

16 La Via WV, Marks MI, Stutman HR. Respiratory syncytial virus puzzle: clinical features, pathophysiology, treatment and prevention. F Pediatr 1992;121;503-10.

17 Sarkkinen HK, Halonen PE, Arstila PP, Salmi AA. Detection of respiratory syncytial, parainfluenza type 2 and adenovirus antigens by radioimmunoassay and enzyme immunoassay on nasopharyngeal specimens from children with acute respiratory disease. F Clin Microbiol 1981;13: 258-65.

18 van Steensel-Moll HA, Jongkind CJ, Aarsen RSR, et al. A problem oriented patient classification system in general problem oriented patient classification system in gent
pediatrics II. Tijdschr Kindergeneeskd 1996;64:99-104.

19 Kapikian AK, Bell JA, Mastrota FM, Johnson KM, Huebner RJ, Chanock RM. An outbreak of febrile illness and pneumonia associated with respiratory syncytial virus infection. American fournal of Hygiene 1961;74:234-8.

20 Wang EE, Law BJ, Stephens D. Pediatric Investigators Collaborative Network on Infections in Canada (PICNIC) prospective study of risk factors and outcomes in patients hospitalized with respiratory syncytial viral lower respiratory tract infection. 7 Pediatr 1995;126:212-9.

21 Sims DG, Downham MA, McQuillin J, Gardner PS. Respiratory syncytial virus infection in north-east England. BMF 1976;ii: $1095-8$

22 Holberg CJ, Wright AL, Martinez FD, Ray CG, Taussig LM, Lebowitz MD. Risk factors for respiratory syncytial virus-associated lower respiratory illnesses in the first year of life. Am f Epidemiol 1991;133:1135-51.

23 Singleton RJ, Petersen KM, Berner JE, et al. Hospitalizations for respiratory syncytial virus infection in Alaska native children. Pediatr Infect Dis f 1995;14:26-30.

24 Statistics Netherlands/Ministry of Welfare, Health and Cultural Affairs. Way of life. Vademecum health statistics 1994. Voorburg: Statistics Netherlands/Rijswijk: Ministry of Welfare, Health and Cultural Affairs, 1994.

25 Hall CB, Walsh EE, Schnabel KC, et al. Occurrence of groups A and B of respiratory syncytial virus over 15 years: associated epidemiologic and clinical characteristics in hospitalized and ambulatory children. F Infect Dis 1990; 162:1283-90.

26 McConnochie KM, Hall CB, Walsh EE, Roghmann KJ. Variation in severity of respiratory syncytial virus infections with subtype. F Pediatr 1990;117:52-62.

27 Kneijber MC, Brandenburg AH, Rothbath $\mathrm{PhH}$, de Groot $\mathrm{R}$, Ott A, van Steensel-Moll HA. The relationship between clinical severity of RSV infection and subtype. Arch Dis Child 1996;75:137-40.

28 Mulholland EK, Olinsky A, Shann FA. Clinical findings and severity of acute bronchiolitis. Lancet 1990;335:1259-61.

29 McConnochie KM, Roghmann KJ. Parental smoking, presence of older siblings and family history of asthma increase risk of bronchiolitis. Am f Dis Child 1986;140:806-12.

30 Wright AL, Holberg C, Martinez FD, Taussig LM. Relationship of parental smoking to wheezing and nonwheezing lower respiratory tract illnesses in infants. F Pediatr 1991;118:207-14.

31 Seaton A, MacNee W, Donaldson K, Godden D. Particulate air pollution and acute health effects. Lancet 1995;345:1768.

32 Schmitzberger R, Rhomberg K, Buchele H, et al. Effects of air pollution on the respiratory tract of children. Pediatr Pulmonol 1993;15:68-74. 